\title{
Três vezes Benedito
}

\author{
Márcio Benchimol Barros \\ Universidade Estadual Paulista Júlio de Mesquita Filho. Marília, São Paulo, Brasil
}

Foi com grande satisfação e alguma surpresa que recebi o sumamente honroso convite dos editores do "Boletim do Museu Paraense Emílio Goeldi. Ciências Humanas" a contribuir com um texto para o dossiê que homenageia o professor Benedito Nunes.

A satisfação tem origem primordialmente na justeza da homenagem e na oportunidade em que ocorre. Não poderia dar início a meu escrito sem um voto de louvor ao Museu Paraense Emílio Goeldi, que empresta sua chancela prestigiosa para registrar, condignamente e em tempo justo, não a ausência do saudoso professor, mas sua presença, tanto na recordação e no sentimento de seus contemporâneos como também nas suas realizações, de que ainda muitas gerações de pósteros se hão de beneficiar. Que a oportuna publicação possa preservar, para uns e para outros, algo desse perfil único, em que a sapiência tão admiravelmente se irmanou à simplicidade e à generosidade; e possa essa imagem constituir-se, não em brônzeo monumento, mas - o que é mais ao espírito do homenageado - em amistoso igarapé, para repouso e encorajamento dos que, em sua terra natal, trilham os caminhos que ele pioneiramente desbravou e pavimentou.

Minha satisfação também teve a ver com a oportunidade que me era oferecida de fazer publicamente minha modesta homenagem ao professor Nunes, unindo, ainda que de maneira simbólica e apenas sob o signo da memória, minha própria trilha particular à sua, coisa que no passado me foi dado realizar apenas de forma limitada. Não tive a felicidade de ser seu aluno, pois, apesar de seu conterrâneo, quis o destino que me graduasse em filosofia na Universidade Estadual de Campinas (UNICAMP). Tampouco posso falar de um convívio propriamente dito com o professor Nunes: meus encontros com ele pouco excederam uma dezena de ocasiões, no mais das vezes em sua residência, ocasiões em que a filosofia foi um assunto apenas um pouco mais frequente do que música, literatura e amenidades. E aqui, precisamente, reside o motivo da surpresa: estes contatos, apesar de, para mim, cheios de significado, a rigor não pareceriam qualificar-me para a importante tarefa que se me deparava. Quiçá, porém, essa relativa distância a partir da qual as circunstâncias da vida me obrigaram a considerar Benedito Nunes me permita acrescentar uma perspectiva interessante para a constituição de sua imagem. É com esta esperança que dedico humildemente à sua memória as linhas seguintes.

A referida distância, de fato, fez com que em minha recordação se distinguissem aspectos da imagem de Benedito Nunes que, suponho, vivam inextricavelmente interpenetrados na daqueles que conviveram com o homenageado e receberam rotineiramente seus ensinamentos. Estes, com efeito, aprenderam a apreciálo como intelectual e como ser humano, e ainda, se me é permitido assim falar, como cidadão amazônico. Nesta expressão, o termo 'cidadão' não tem o seu sentido usual

BARROS, Márcio Benchimol. Três vezes Benedito. Boletim do Museu Paraense Emílio Goeldi. Ciências Humanas, v. 6, n. 2, p. 395-399, maio-ago. 2011.

Autor para correspondência: Márcio Benchimol Barros. Universidade Estadual Paulista Júlio de Mesquita Filho. Faculdade de Filosofia e Ciências. Campus de Marília. Av. Hygino Muzzi Filho, 737. Cidade Universitária. Marília, SP, Brasil. CEP 17525-900 (benchimolbarros@ gmail.com).

Recebido em 19/07/2011

Aprovado em 20/07/2011

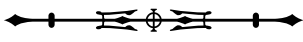


e rotineiro, redutoramente político: em se tratando do homenageado, o foco principal nunca poderia ser o Estado ou a sociedade, mas sempre a cultura. Chamando-o cidadão amazônico, quero aludir tanto à sua atuação docente em prol da cultura na região, a seu zelo na difusão do genuíno saber filosófico no estado, como à sua consciente, reiterada e frutífera inserção no peculiarmente rico contexto fornecido pela história artística e intelectual de nossa região. Para mim, dizia eu, esses três aspectos apresentaram-se em separado: tive de tomar contato com eles não simultânea, mas sucessivamente. Primeiro conheci o intelectual, depois a pessoa humana e só posteriormente comecei a perceber mais claramente a sua relação com a história cultural amazônica, campo em que ainda me considero um iniciante. Peço, então, licença para esboçar em algumas poucas palavras as impressões que me ficaram destes aspectos, na ordem pela qual tomei com eles contato.

Comecemos então pelo intelectual. Com este tive os primeiros contatos quando já era estudante de filosofia na UNICAMP. Anteriormente, o nome Benedito Nunes se me tornara conhecido apenas por intermédio dos comentários entusiasmados de amigos, no curto tempo em que fui estudante do curso de física da Universidade Federal do Pará (UFPA), e pela capa de um livro que, motivado por semelhantes comentários, fazia tenção de no futuro ler (era "O Dorso do Tigre"). E em meus estudos de graduação em filosofia, já longe da terra natal, conheci o intelectual Benedito Nunes da mesma forma que como qualquer outro colega de curso poderia tê-lo feito, ou seja, por meio de textos ali disponíveis, conferências ali pronunciadas, arguições em bancas de pós-graduação, etc. Portanto, a imagem que me fazia deste intelectual não podia ser substancialmente diversa daquela que qualquer outro estudante de filosofia de minha faculdade - como também de muitas outras - dele teria feito.

Era tal imagem a de um modelo, porém em um sentido nostálgico: como que a imagem de um ideal fundamente ansiado, mas aparentemente não mais alcançável, risonha imagem de tempos mais livres e felizes do espírito. Creio, de início, que qualquer de meus contemporâneos de estudos filosóficos que tivessem tido contato com as produções de Benedito Nunes tenderia a admirar-lhe, não somente o brilho do intelecto, mas, acima de tudo, a abrangência do espaço filosófico que este intelecto ousou abarcar e iluminar. Em tempos em que a obtusa equiparação entre excelência, especialização e produtividade já começava a formatar perversamente toda a vida acadêmica, indo inclusive refletir-se na própria estruturação dos cursos de graduação, e em que amedrontados pesquisadores abandonavam já de bom grado as vastidões perigosas do pensamento para entrincheirar-se em campos cada vez mais específicos de investigação, nestes tempos, dizia eu, o amplo arco que as análises de Nunes costumava descrever em seus escritos teria de aparecer como temeridade desusada, tanto mais admirável quanto menos exposta se achava à crítica miúda dos especialistas. Pois ele mesmo estava longe de desprezar o estudo específico e particularizado: apenas não o encarava como objetivo supremo, mas como ponto de ancoragem e preparação para o livre voo do pensamento. Pode-se mesmo dizer que escreveu muitas vezes, e com todo o direito, como especialista, porém a especialização não lhe era meta nem canga intelectual, e sim instrumento livremente manejável.

Outro importante elemento desta imagem de Benedito Nunes como o intelectual do olhar abrangente, a sobrepassar soberano as compartimentações com que a academia procura capturar o espírito, era sua forte ligação com a literatura e sua atuação destacada no campo da crítica literária, pela qual seu nome era reconhecido não apenas entre os estudantes e pesquisadores filosóficos, mas também entre os que se ocupavam com as belas letras. Mestre inconteste em matéria literária, seu rico espírito, que combinava claro intelecto com refinada sensibilidade artística, via-se solicitado tão fortemente, embora de maneira distinta, tanto por Guimarães Rosa, Clarice Lispector, Dalcídio Jurandir e Mário Faustino quanto por Kant, Heidegger, Merleau-Ponty e Platão. Bravamente, recusou sujeitar-se 
a limitações que mais correspondiam às conveniências das instituições do que à natureza das coisas. Pertencialhe certamente a rara percepção da unidade intrínseca entre todas as manifestações do espírito, e do profundo copertencimento entre filosofia e arte, como campos intercomunicantes em que se cristaliza a experiência humana em geral. Assim é que, também como crítico literário, não abandonava o olhar da filosofia; e, seja dito, contar-se-ão, talvez, com os dedos de uma única mão aqueles que em nosso país souberam dotar a análise literária de profundidade filosófica com o rigor com que o fez Benedito Nunes.

E da mesma forma como não abandonava a filosofia ao fazer crítica literária, também sua produção filosófica tinha algo de literário. "É um estilista!", comentou-me certa vez um admirado colega de turma que lhe havia ouvido uma palestra. Tinha fundamento a admiração: Benedito Nunes tinha realmente estilo ao escrever, coisa hoje em dia bastante rara entre os ensaístas filosóficos e que já o era ao tempo em que o comentário foi feito. Rigor conceitual, correção teórica e coerência argumentativa não lhe eram suficientes: seus escritos precisavam trazer sua marca autoral, tinham de ser realmente seus escritos. A frase elegante e fluida, a sintaxe requintada, mas clara, as palavras escolhidas com o vagar de quem colhe gemas esquecidas sob a superfície da linguagem, ou busca as notas certas para uma melodia pressentida, tudo isto denunciava que, por trás de todos os elementos textuais, havia um autor, e não um mero amontoador de palavras. Que contraste com o rançoso jargão acadêmico usual, cheio de expressões feitas, metáforas deslocadas e inconscientes e que, quanto mais a produção de textos em escala industrial se transforma no único e dourado sonho das instituições universitárias, mais se aproxima do ramerrão neutro dos relatórios e formulários! Em Nunes, a 'passagem para o poético' não era violência cometida à prosa filosófica, mas consequência da percepção da unidade profunda entre arte e filosofia, consciência essa que, refletindo-se em seu estilo, rematava-lhe a aura de independência intelectual que sempre o distinguiu em minha percepção.
Foi quando essa imagem já se havia desenhado para mim que tive por primeira vez oportunidade de travar contato pessoal com o professor Nunes. Ocorreu isso já em meu tempo de estudante, por intermediação amigável do colega Ernani Chaves, do então Departamento de Filosofia da UFPA. Novos encontros se deram durante minha atuação como professor substituto neste mesmo departamento, entre os anos de 1993 e 1994, renovandose posteriormente até data recente, quando já integrava o Departamento de Filosofia da Universidade Estadual Paulista Júlio de Mesquita Filho (UNESP), sediado em Marília (SP), coincidindo um deles com a ocasião de uma entrevista que, juntamente com o recém mencionado colega, realizei com o professor Nunes. A realização desta entrevista, cuja matriz em áudio ainda conservo, me havia sido dada como incumbência pela coordenaçã̃o da revista "Transformação", vinculada a meu atual departamento, e apareceu em sua edição de número 31/1, em 2008, motivo pelo qual imagino que deva constituir um dos últimos testemunhos dados pelo pensador sobre sua trajetória intelectual e sua obra.

Foi evidentemente por meio destes encontros que à imagem do intelectual foi-se somando a do homem concreto. Mas, neste ponto, creio nada ter a acrescentar àquilo que já é sabido e testemunhado de sobejo por todos que o conheceram. Ocioso demorar-me aqui a lembrar a gentileza proverbial, a generosidade e a simpatia despojada que manifestamente o caracterizavam. Limito-me a ressaltar o contraste em que tudo isso estava em relação à soberba arrogância e presunção que já me acostumara ver artificiosamente ornar intelectos muito menos ricos. Benedito Nunes realmente ajudou-me a diagnosticar a enfatuação como sintoma de pobreza de espírito, e seu exemplo sempre me auxiliou a evitar essa deformação de caráter que é a vaidade intelectual.

Eis-me, então, chegado ao ponto em que talvez se esperaria que dissesse algumas palavras sobre a relação entre o homenageado e a história intelectual e artística da Amazônia. Tenho, entretanto, de frustrar esta expectativa, especialmente por faltar-me competência neste campo, em 
que muito mais tenho a aprender do que a acrescentar. Ao invés disso, dar-me-ei por contente se puder dizer alguma coisa sobre o significado que, para mim e talvez para outros, encerra a existência concreta de Benedito Nunes como cidadão belenense, sua opção consciente por permanecer vivendo e atuando na capital paraense, quando lhe seria fácil instalar-se em meio em que seus esforços obtivessem mais imediatamente o destaque e a recompensa que lhe são devidos. Não se deve aqui falar de abnegação, que é um conceito por demais moralizante e, aliás, injusto, se considerarmos toda a riqueza única da cultura amazônica. Prefiro ver nessa opção, por parte de Nunes, muito mais um reconhecimento dessa riqueza e uma profunda consciência de representar um elo absolutamente importante e significativo na história dessa cultura.

A própria homenagem que o Museu Goeldi presta a Benedito Nunes já sinaliza o lugar de destaque que este ocupa na história cultural da Amazônia, pois que a mesma instituição constituiu-se, desde sua fundação, em um importante sujeito desta história. Creio, porém, ver entre as atuações de homenageado e homenageante uma unidade simbólica cuja apreciação requer que as consideremos no contexto mais amplo das relações históricas entre a Amazônia e a cultura ocidental como um todo. Diria, então, que tanto a atuação do Museu Goeldi como a de Benedito Nunes visam estabelecer uma firme ligação entre estes dois pólos, porém, em movimentos, por assim dizer, contrários, mas também complementares.

O Museu Goeldi simboliza e corporifica, de forma exemplar, o grande interesse intelectual que a Amazônia despertou para a cultura ocidental desde a Renascença, quando a descoberta do Novo Mundo ensejou o surgimento progressivo de novas formas de concepção da natureza e do homem. Testemunham este interesse nascente não só as obras dos primeiros naturalistas, mas também, no campo da especulação filosófica, o célebre ensaio que Montaigne escreveu sobre os canibais, em que os hábitos de nossos antepassados tupinambás apareceram sob inesperada luz favorável em comparação à brutalidade dos conquistadores e inquisidores europeus. Será este interesse uma manifestação particular do fascínio que a natureza tende a exercer sobre o homem civilizado moderno, fascínio a que Schiller deu expressão poeticamente transfigurada, porém exemplar, em seu ensaio "Sobre poesia ingênua e sentimental". "Com doloroso anseio", diz o poeta e filósofo, referindose à natureza, "desejamos para lá retornar, tão logo comecemos a experimentar os tormentos da cultura e, no distante exílio em que nos expatriou o artifício, ouvimos a tocante voz materna". Foi certamente a esta voz que respondeu Alexander von Humboldt, irmão de Wilhelm von Humboldt e, como este, amigo e colaborador de Schiller e do entusiástico naturalista Goethe, quando, em 1800, veio ter à mata amazônica, a fim de explorar e descrever sua fauna, flora, hidrografia, bem como seus habitantes e seus costumes. Vindo da Amazônia venezuelana, o apaixonado naturalista penetra o território nacional, e (gosto de pensar) talvez houvera chegado à província de Santa Maria de Belém, não fora impedido pelo governo português, que brutamente cortou-lhe o passo. Mas aquilo que a coroa imperial negou a Humboldt, a República iria oferecer a um sucessor mais feliz, Emílio Goeldi, e a instituição que leva seu nome logo se constituiu no pólo mais avançado da pesquisa sobre a natureza e o homem amazônico. Sua atividade revela para o mundo e para os próprios amazônidas, sob o prisma objetivo da ciência, a fauna, a flora e as culturas humanas que a região encerra.

Já Benedito Nunes respondeu a outro chamamento: não à 'tocante voz materna' da natureza, pois que viveu cercado dela, mas sim à voz universalista da cultura, que chama a todos os povos caídos no círculo da civilização a integrarem-se, como sujeitos conscientes, no vasto campo da experiência humana em geral. Ressoa nesta voz o "sou homem e nada humano me é estranho", de Terêncio, esse lema que foi também o de Montaigne, e que traduzia o credo humanístico que os irmãos Humboldt compartilhavam com seus celebrados e já mencionados 
companheiros. Apenas que aqui o movimento ocorre não do universal em direção ao particular, mas deste em direção àquele. Em Nunes, diria eu, toma corpo um movimento no qual uma autoconsciência amazônica abre seu caminho em direção ao todo da cultura ocidental, procurando comunicar-se com ela e absorver em si seus elementos. Faz parte desta autoconsciência coletiva certamente a percepção básica de pertencermos todos a um contexto cultural particular, de partilharmos traços absolutamente peculiares e característicos de nossa região, que englobam tanto hábitos linguísticos e alimentares como nossa herança histórica comum, nossa profunda ligação sentimental com a paisagem amazônica e nossa preocupação com seu destino. Mas, além disso, integra-a a percepção de que fazemos parte, por direito e intrinsecamente, de uma coletividade muito mais ampla, que virtualmente nos conecta a todas as culturas e a toda a história humana. É esta percepção que faz surgir um anseio especial que suponho fazer parte da experiência íntima de todos os que se dedicaram, de uma forma ou de outra, às coisas da cultura em nossa região: o anseio por romper o isolamento em que a própria natureza e certos sucessos políticos e econômicos da vida nacional acabaram por nos lançar, franqueando o caminho capaz de nos conduzir ao campo aberto e fecundo da cultura humana em geral, para com ele estabelecer comunicação sólida e duradoura. Tal anseio manifesta-se na literatura de um Dalcídio Jurandir ou de um Haroldo Maranhão, na poesia de Max Martins ou de Paes Loureiro, na música de Waldemar Henrique e Gama Malcher, bem como no trabalho crítico e formador de Francisco Paulo Mendes, querido mestre de Benedito Nunes. E também, evidentemente, na atuação deste último, e não apenas em sua ocupação crítica com nossos literatos e intelectuais, mas especialmente em seu envolvimento com a investigação filosófica e com o ensino da filosofia. É neste envolvimento que vejo manifestar-se em grau máximo aquele impulso ao universal a que há pouco me referia, pois o universal é o próprio elemento em que se move o espírito filosófico. Nos conceitos filosóficos, sedimenta-se o essencial de milênios de experiência humana; em suas discussões são examinados todos os critérios epistemológicos, políticos, morais e estéticos que balizaram essa existência durante toda a história. Por isso, o caminho da Amazônia em direção à cultura humana universal não poderia deixar de passar pela via da filosofia. Abrir esta via foi a tarefa que Benedito Nunes, quer-me parecer, colocou a si próprio. Terá sido este seu compromisso interior com nossa terra. Sua atuação docente e seu estímulo à investigação filosófica trouxeram nova vitalidade à produção cultural da região, forçando-a a ascender a um novo patamar. Pode a Amazônia ter sido até aqui apenas objeto passivo do conhecimento, ou objeto mítico à disposição das campanhas publicitárias, ou ainda objeto da cobiça, seja dos que não se importariam em destruí-la para preservar seus interesses, seja dos que, sob o pretexto de tutelá-la, a espreitam cheios de compridos olhares: a partir do novo patamar instaurado pela ação do professor Nunes, podemos realmente esperar que um dia ela passe a constituir-se em região capaz de produzir uma reflexão crítica sobre si mesma, uma autoconsciência que saiba avaliar sua história, seus problemas, seu lugar no mundo e seu significado para a humanidade, que a cada dia tendem a se tornar mais importantes e decisivos.

Não temos condições de saber como e quando tal perspectiva se há de confirmar, mas não cabe dúvida de que ela só pôde despontar em nosso horizonte graças ao saudoso mestre da Travessa da Estrela.

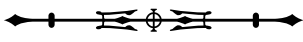

